\title{
Synthesis and Antimicrobial Activity of a Silver-Hydroxyapatite Nanocomposite
}

\author{
Marcos Díaz, ${ }^{1}$ Flora Barba, ${ }^{2}$ Miriam Miranda, ${ }^{3}$ Francisco Guitián, ${ }^{4}$ Ramón Torrecillas, ${ }^{3}$ \\ and José S. Moya ${ }^{1}$ \\ ${ }^{1}$ Department of Biomaterials and Bioinspired Materials, Instituto de Ciencia de Materiales de Madrid (ICMM-CSIC), \\ Cantoblanco, 28049, Madrid, Spain \\ ${ }^{2}$ Department of Ceramic, Instituto de Cerámica y Vidrio (ICV-CSIC), Cantoblanco, 28049, Madrid, Spain \\ ${ }^{3}$ Department of Nanostructured Materials, Centro de Investigación en Nanomateriales y Nanotecnología (CINN-CSIC), \\ Francisco Pintado Fe 26, 33011, Oviedo, Spain \\ ${ }^{4}$ Instituto de Cerámica de Galicia, Universidad de Santiago de Compostela, 15706, Santiago de Compostela, Spain
}

Correspondence should be addressed to Ramón Torrecillas, r.torrecillas@cinn.es

Received 21 August 2008; Revised 14 January 2009; Accepted 13 March 2009

Recommended by Maryam Tabrizian

A silver-hydroxyapatite nanocomposite has been obtained by a colloidal chemical route and subsequent reduction process in $\mathrm{H}_{2} / \mathrm{Ar}$ atmosphere at $350^{\circ} \mathrm{C}$. This material has been characterized by TEM, XRD, and UV-Visible spectroscopy, showing the silver nanoparticles $(\sim 65 \mathrm{~nm})$ supported onto the HA particles $(\sim 130 \mathrm{~nm})$ surface without a high degree of agglomeration. The bactericidal effect against common Gram-positive and Gram-negative bacteria has been also investigated. The results indicated a high antimicrobial activity for Staphylococcus aureus, Pneumococcus and Escherichia coli, so this material can be a promising antimicrobial biomaterial for implant and reconstructive surgery applications.

Copyright () 2009 Marcos Díaz et al. This is an open access article distributed under the Creative Commons Attribution License, which permits unrestricted use, distribution, and reproduction in any medium, provided the original work is properly cited.

\section{Introduction}

The occurrence of bone fractures due to the growing number of traffic accidents, as well as the musculoskeletal conditions requiring reconstructive surgery derived from the increase in the human life expectancy, has led to an increasing number of people in the world having at least one orthopedic or dental implant. In addition to the considerable impact on the health and quality of life that these types of surgery have on the population, they impose an important burden for the economy of countries. Only in the United States, the number of orthopedic procedures performed each year-including knee arthroplasty, total and partial hip replacement, and spinal fusion-increased by nearly 25 percent between 1997 and 2005, climbing from 822000 to 1.3 million, according to the latest News and Numbers summary from the Agency for Healthcare Research and Quality [1]. The same report finds also that the costs related to hospital stays for orthopedic procedures totalled $\$ 31.5$ billion. It has also been estimated that 2 million new dental implants are performed every year
[2]. Therefore the need for reliable and economically feasible biomaterials for healing fractures or treating musculoskeletal diseases has increased in the last years.

Hydroxyapatite ( $\left.\mathrm{HA}, \mathrm{Ca}_{10}\left(\mathrm{PO}_{4}\right)_{6}(\mathrm{OH})_{2}\right)$ is the main mineral component of bone, and its synthetic form is one of the most widely used biomaterials for reconstruction of the skeleton due to the lack of local or systemic toxicity together with its osteoconductive properties [3-5]. It is used as an implant material both in its bulk mainly porous form, for filling in or reconstructing bone defects, and as a thin coating on metals, titanium and CoCrMo alloys, for hip, knee, and dental prostheses. Although success rates of these kinds of implants are dependent on bone-implant osteointegration, the success and long-term survival of the implants are also dependent on the prevention of bacterial infection after implant placement.

Despite the use of perioperative antimicrobial prophylaxis and laminar flow operating rooms, the infection rates associated with prosthetic joints range between $1 \%$ and $9 \%$, depending on the type of implant [6]. Although the 
infection-associated implant failures occur less frequently than aseptic ones, they are the second reason for revision surgery in the case of total hip replacements [7] and represent the most devastating complication with high morbidity and elevated medical cost. Moreover, infection rates after surgery revision are $40 \%$ higher than after primary replacement [8]. Studies on orthopaedic patients revealed that the estimated average total direct cost associated with an infected case ranges between $\$ 15000$ and $\$ 30000$-an increase of approximately 3 times than the initial intervention-and shown that the patients spent on average 14 extra days in the hospital after readmission [9]. In the case of dental implants, complications derived from an implant-associated infection do not usually require patient hospitalization, but lead to a detriment in the patient quality of life and satisfaction because it is one of the reasons for early failures by lack of osseointegration and the major cause of late failures [10].

Therefore, efficient prevention of implant-associated infections to avoid surgical revisions and expensive and long hospital stays that increase the patient morbidity is of paramount importance. One common and accepted strategy to treat and prevent infections associated with orthopedic implants is to deliver antibiotics in a controlled manner at the site of implantation in order to administer high local doses without exceeding the systemic toxicity of these drugs [1113]. Antibiotic release has been achieved using a wide variety of biocompatible materials in the form of coatings or beads. Some of these materials are polymers (polyurethane, polyhydroxylalkanoates, polymethylmethacrylate (PMMA), poly L-lactic acid (PLA), poly(lactic-co-glycolic) acid (PLGA), etc.), and synthetic hydroxyapatite (HA) [14-16]. Although controlled drug delivery has been shown for nonbiodegradable polymers, such as PMMA, its effectiveness, however, is strongly dependent on the antibiotic release profile from the polymer, which is a function of the chemical similarity between the drug and the polymer, as well as of the physical properties of the polymer itself $[14,15,17]$. Moreover, the nonbiodegradable polymers do not resorb and require a subsequent operation for removal.

The biodegradable antibiotic-loaded polymer coatings, such as PLA or PLGA, are able to resorb, so it overcomes this latter disadvantage, but its high hydrophobicity is another important drawback, since it places practical constraints on formulating devices with sufficient antibiotic loading and dispersion for reliable delivery of antimicrobials [14].

A good approach to the local treatment of implantassociated infections is the use of HA coatings for antibiotics delivery, exploiting the osteoconductive properties of this material. However, the loading and release rate is strongly dependent on the acidic or basic character of antibiotics. Acidic antibiotics are incorporated with greater efficiency than basic antibiotics because of the calcium-chelating properties of the carboxylate groups. However, through calciumcarboxylate chelating interactions, the acidic antibiotics are retained to a greater extent relative to the basic antibiotics [15]. This fact imposes certain limitations in cases that require the use of acidic antibiotics, for example amoxicillin.

The capacity of certain bacterial strains to develop resistance against antibiotics has aroused an increasing interest for the controlled delivery of other antibacterial agents with a broader activity and low incidence of resistance, such metals like silver or zinc, being an alternative strategy to avoid the formation of adhesive bacterial films [18]. The antibacterial properties of silver at low concentrations over a wide range of pathogens, including the common bacterial strains involved in implant-associated infections as well as the lack of toxicity for the mammalian cells, are well known [19-24].

Most silver-containing antimicrobial biomaterials consist of either elemental silver or $\mathrm{Ag}^{+}$(silver salts or silver complexes) incorporated into organic (polymers) or inorganic (bioglasses and HA) matrices. While the in vitro antimicrobial activity of silver-containing polymers (polyamides, polyurethane, and PMMA) and bioglasses has been extensively studied [25-28], the bactericide action of Ag-HA materials has been reported in less extension. Recently, Agloaded HA composites obtained by ion-exchange methods (sol-gel or coprecipitation) have been reported [29-32]. These routes involve the silver substitution for calcium, resulting in a Ca-deficient hydroxyapatite. The antimicrobial response of these materials is good, but they have two main drawbacks: (i) the depletion of calcium could have negative effects on the structural stability of nano HA [31] as well as on its osteoconduction ability [32]; (ii) a rapid release of silver, depending on the $\mathrm{pH}$, can take place. These facts have brought out an increasing interest on silver nanoparticles as bactericidal reservoir due to their low solubility in aqueous media. Studies on nanosilver-loaded polymer films reveal that the duration of silver release is strongly dependent on the total amount of silver nanoparticles [19]. The biocide activity of colloidal silver nanoparticles is influenced by their size-the smaller the particles, the greater antimicrobial effect [22]-however, the aggregation problems of nanoparticles are well known. A common solution to avoid this disadvantage is to support the nanoparticles on the surface of different substrates. Despite the potential clinical applications of nAg-HA composites due to the combination of osteoconductive and bactericide properties, there are few examples in the literature of silver nanoparticles supported onto hydroxyapatite particles. These materials have been obtained by cosputtering of silver and hydroxyapatite to form coatings on titanium surfaces [33], and by in situ reduction of silver cations on the surface of HA particles [34]. In the present work, a simple and low-cost method to support silver on the surface of hydroxyapatite to obtain a nano-nano hybrid composite, containing $1 \mathrm{wt} \%$ of elemental silver, with antimicrobial activity is presented.

\section{Materials and Methods}

2.1. Preparation. The preparation method comprises two steps: (i) synthesis of HA nanoparticles by a sol-gel processing route, and (ii) precipitation of $\mathrm{Ag}_{2} \mathrm{O}$ nuclei from silver nitrate aqueous solution and further reduction with an $\mathrm{Ar} / \mathrm{H}_{2}$ gas mixture at low temperature to obtain silver nanoparticles attached onto nano-HA.

The precursors employed in the HA nanoparticles were triethylphosphite (98\%, Aldrich) and calcium nitrate 


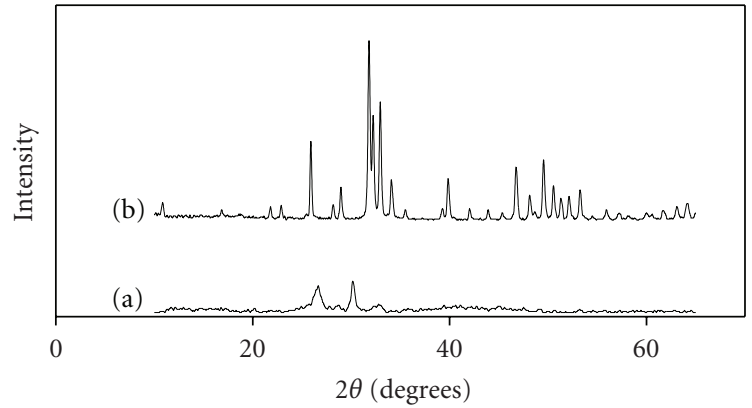

FIGURE 1: XRD patterns corresponding to different stages of HA synthesis: (a) amorphous dry gel; (b) crystallization at $550^{\circ} \mathrm{C}$.

tetrahydrate ( $\geq 99 \%$, Fluka). Aqueous solutions $3 \mathrm{M}$ were prepared for each precursor in order to obtain a final $\mathrm{Ca} / \mathrm{P}$ molar ratio of 1.67. The phosphorous solution was added dropwise to the calcium solution under vigorous stirring while maintaining the temperature at $65^{\circ} \mathrm{C}$ and $\mathrm{pH}=8$. The $\mathrm{pH}$ was controlled by addition of $\mathrm{NH}_{4} \mathrm{OH}(28 \% \mathrm{w} / \mathrm{w}$, Fluka) aqueous solution. The resulting colloidal suspension was stirred at $70^{\circ} \mathrm{C}$ for two hours and then aged at room temperature for 24 hours to obtain white and viscous gel. The gel was dried in a vacuum chamber at $100^{\circ} \mathrm{C}$ until the solvent was completely removed. The dry powder was ground and calcined at $550^{\circ} \mathrm{C}$ for 2 hours. A well-crystallized HA powder was obtained.

In order to prepare the nAg-HA composite $5 \mathrm{~g}$ of the HA powder obtained in the previous synthesis were suspended in $50.55 \mathrm{~mL}$ of distilled water (9 $\mathrm{wt} \%$ of solids loading). Subsequently, the suspension $\mathrm{pH}$ was adjusted to 5 by adding dropwise a $0.1 \mathrm{~N} \mathrm{HNO}_{3}$ aqueous solution under stirring at $60^{\circ} \mathrm{C}$. Then, $10 \mathrm{~mL}$ of a $4.7 \times 10^{-2} \mathrm{M} \mathrm{AgNO}_{3}$ aqueous solution were added to obtain an nAg-HA composite containing $1 \mathrm{wt} \%$ of metallic silver. Under continuous stirring, the $\mathrm{pH}$ was adjusted to 9 by adding dropwise a $1 \mathrm{M} \mathrm{NaOH}$ aqueous solution to precipitate $\mathrm{Ag}^{+}$cations as $\mathrm{Ag}_{2} \mathrm{O}$, according to the potential-pH diagram in aqueous solution for silver [35]. The suspended white powder slowly turned to gray, indicating the presence of $\mathrm{Ag}_{2} \mathrm{O}$ precipitation nuclei. Finally, the suspension was filtered and washed twice with distilled water at $60^{\circ} \mathrm{C}$. The resulting powder was dried at $60^{\circ} \mathrm{C}$ and calcined at $350^{\circ} \mathrm{C}$ for 2 hours in a gas mixture of $\mathrm{Ar} / \mathrm{H}_{2}$ 90/10 in order to reduce the silver oxide to metallic silver, yielding a pale brown powder. All steps of this synthesis were carried out in absence of light to avoid the spontaneous reduction of silver cations to elemental silver.

2.2. Characterization Techniques. X-ray powder diffraction (XRD) patterns were registered using a Bruker D8 Advance diffractometer with a $\mathrm{Cu} \mathrm{K}_{\alpha}$ radiation source at a scan speed of $0.5^{\circ} / \mathrm{min}$ and a step scan of $0.02^{\circ}$.

The powder particle size distribution was carried out in a instrument Coulter? LS 13320 using laser radiation $(\lambda=$ $750 \mathrm{~nm})$.

Transmission electron microscopy images were recorded on a Jeol 2000 FXII instrument operating at $200 \mathrm{kV}$.

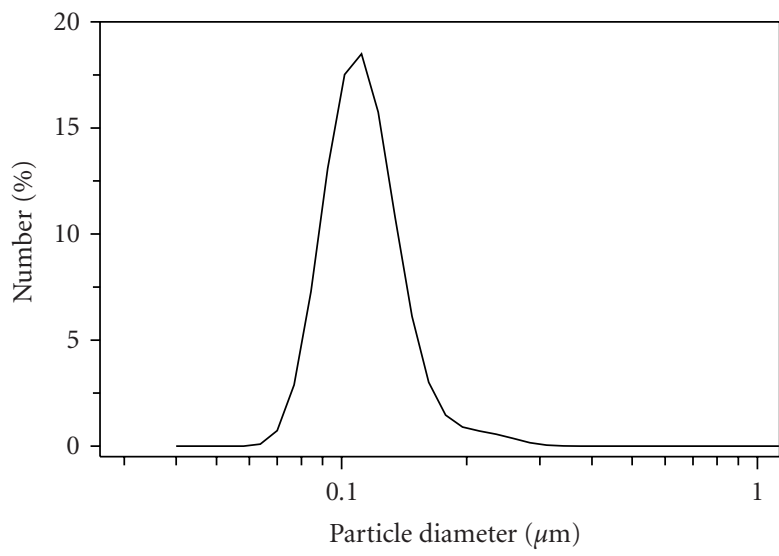

Figure 2: Particle size distribution of hydroxyapatite powder.

UV-vis spectroscopy was performed using a Cary 4000 uv-vis spectrophotometer.

2.3. Antimicrobial Activity. To investigate the bactericidal effect of the nAg-HA composite, two types of tests were performed as follows.

(i) A qualitative diffusion disk test using $10^{5}$ colony forming units (CFUs) of the Staphylococcus aureus (Sa), Pneumococcus (Pn), and Escherichia coli (Ec). They were cultured on LB agar plates. Pellets of $0.05 \mathrm{~g}, 8 \mathrm{~mm}$ in diameter, pressed at $100 \mathrm{MPa}$ of $\mathrm{HA}$ (as control) and of nAg-HA composite were located at the center of the Petri plate. The plates were incubated for 24 hours at $37^{\circ} \mathrm{C}$. The microbial inhibition zone was observed under optical microscope. The inhibition zone size around three pellets corresponding to the nAg-HA sample and the control for the different bacterial cultures was averaged.

(ii) A quantitative analysis using $10^{5} \mathrm{CFU}$ of a Gramnegative bacterium Ec strain $B$ which were cultured on LB agar plates containing different concentrations of composite, 1,5 , and $10 \mathrm{mg} / \mathrm{cm}^{3}$, corresponding to 10,50 , and $100 \mu \mathrm{g} / \mathrm{cm}^{3}$ of silver nanoparticles, respectively. Silver-free HA LB agar plates cultured under the same conditions were used as a control. The plates were incubated for 24 hours at $37^{\circ} \mathrm{C}$, and the numbers of colonies were counted. The counts on the three plates corresponding to each sample were averaged.

\section{Results and Discussion}

The crystallization process of the hydroxyapatite powder is shown in Figure 1. The granulometric analysis (Figure 2) revealed a stretch size distribution with an average size $\left(\mathrm{d}_{50}\right)$ of $137 \mathrm{~nm}$, in agreement with the TEM images of the powder shown in Figure 3.

The XRD pattern of the resulting HA-nAg powder is shown in Figure 4. The reflections at $38.1^{\circ}$ and $44.3^{\circ}$ correspond to metallic silver. No other phases but HA were 


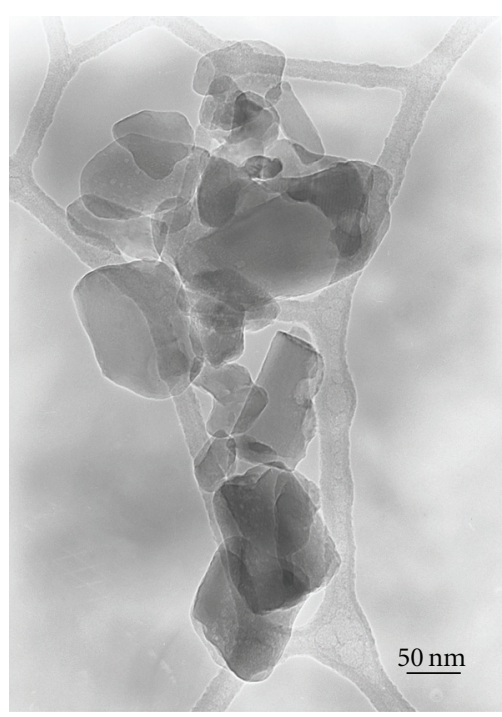

FIGURE 3: TEM image showing the size and morphology of the HA nanoparticles synthesized.

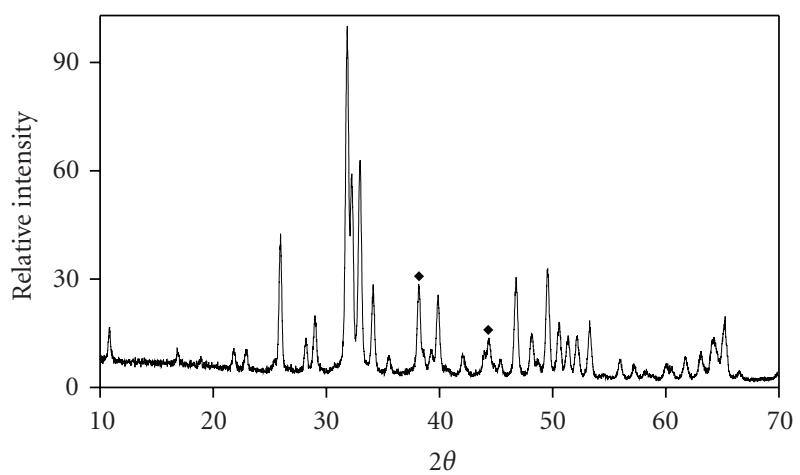

FIGURE 4: XRD pattern corresponding to the $1 \mathrm{wt} \%$ Ag-containing HA composite after reduction treatment $(\checkmark \mathrm{Ag}(0))$.

detected, which indicates that destabilization or dissolution of hydroxyapatite has not taken place during the Ag nanoparticles synthesis.

The average particle size of silver, calculated from the Scherrer formula, was found to be $65 \mathrm{~nm}$. TEM images show in Figure 5 a size distribution of globular-shape silver particles that range between less than $20 \mathrm{~nm}$ and $100 \mathrm{~nm}$. The majority of larger silver particles occur onto aggregates of HA particles. This fact could be related with a partial destabilization of HA particles in aqueous suspension that gives rise to the formation of aggregates, where the growth of $\mathrm{Ag}_{2} \mathrm{O}$ nuclei could be favored. It is well known that the size of the particles formed from a solution is inversely proportional to the number of small precipitation nuclei, so the greater the number of these, the smaller the particles obtained [36]. The decrease of the specific surface of HA aggregates can affect the distribution of the precipitation nuclei at these sites, leading to the growth of the particles. On the other hand, bigger Ag particles can also be formed by coalescence of smaller ones during the reduction process.

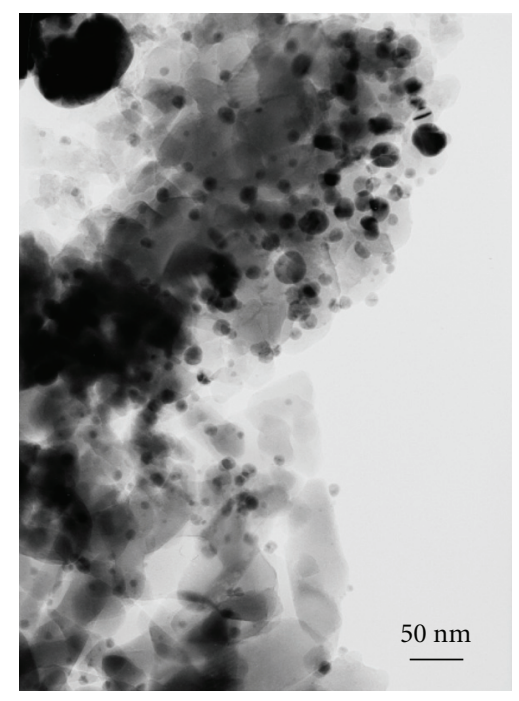

(a)

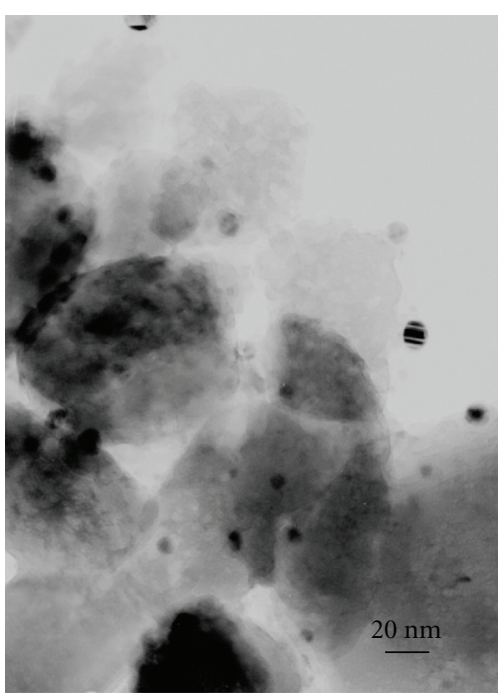

(b)

FIgURE 5: (a) TEM image showing the size distribution of $\mathrm{Ag}$ nanoparticles; (b) high magnification TEM image showing $\mathrm{n}-\mathrm{Ag}$ particles less than $20 \mathrm{~nm}$ attached on the HA surface.

The pale brown color of the Ag-HA powder is due to the excitation of surface plasmon vibrations of silver nanoparticles on the HA surface. The UV-VIS spectrum is shown in Figure 6 . The broad band centered at $450 \mathrm{~nm}$ agrees with a size distribution due to the partial aggregation of silver nanoparticles [34]. The colloidal silver solutions are yellow when the nanoparticles are well dispersed. However, if the particles are close enough, there is an overlap of the surface plasmon vibrations between neighboring particles and results in changes in the optical properties. This can occur due to the aggregations of the silver nanoparticles, leading to an effective decrease in the average interparticle distance. The absence of higher-wavelength features (see Figure 6) indicates the lack of anisotropy of the silver nanoparticles, in good agreement with the TEM images. 


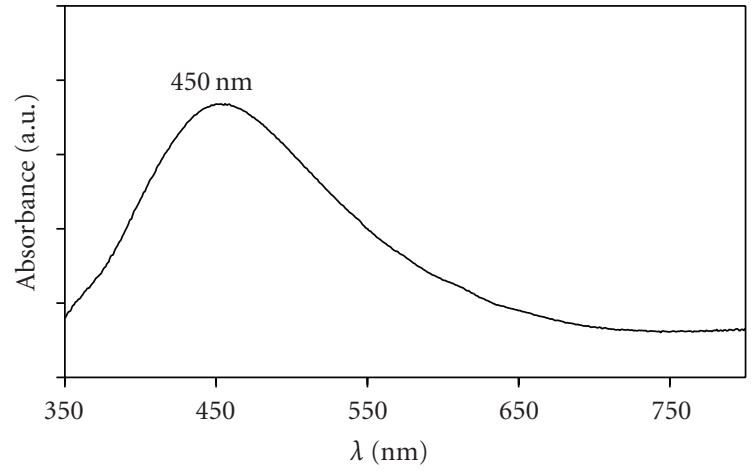

Figure 6: UV-vis spectrum of the Ag-HA powder showing the surface plasmon band of silver nanoparticles.

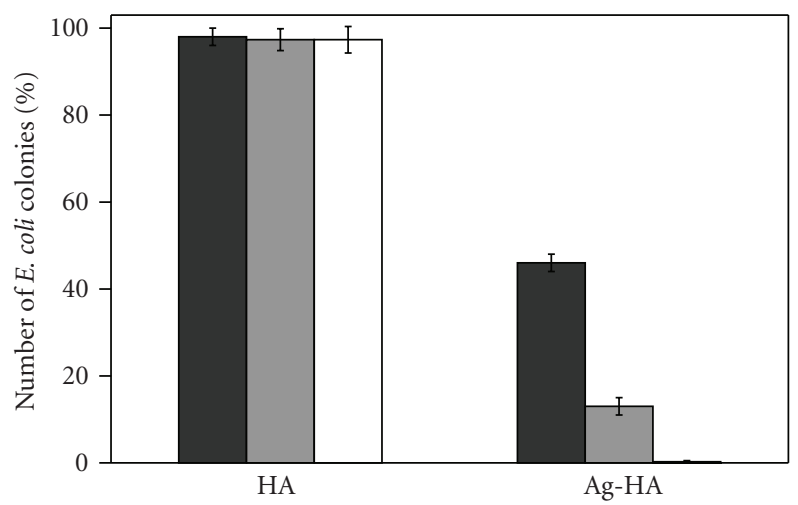

$$
\begin{aligned}
& 10 \mu \mathrm{g} / \mathrm{cm}^{3} \\
& 50 \mu \mathrm{g} / \mathrm{cm}^{3} \\
& 100 \mu \mathrm{g} / \mathrm{cm}^{3}
\end{aligned}
$$

Figure 7: Number of E. coli colonies as a function of the concentration of silver nanoparticles expressed as a percentage of the number of colonies grown on silver-free control plates.

The diffusion disk tests showed, in all the cases, a similar exclusion area that appears only around the nAg-HA composite pellets, as it is reported in Table 1. These results show that a silver concentration of $10000 \mathrm{ppm}$ is ended up in toxicity for common Gram-positive and Gram-negative bacteria. Figure 7 shows the number of bacterial colonies grown on LB plates containing 1,5 , and $10 \mathrm{mg} / \mathrm{cm}^{3}$ of nAgHA composite and pure HA as control, when approximately $10^{5} \mathrm{CFU}$ were cultured in the plates. After 24 hours, the presence of silver nanoparticles at a concentration of 10 and $50 \mu \mathrm{g} / \mathrm{cm}^{3}$ inhibited the bacterial growth by $62 \%$ and $88 \%$, respectively, while a concentration of $100 \mu \mathrm{g} / \mathrm{cm}^{3}$ caused $100 \%$ inhibition of bacterial growth.

These results show a strong bactericidal effect against $\mathrm{Sa}, \mathrm{Pn}$, and Ec. In the particular case of Gram-negative bacterium E. coli, it is slightly lower than colloidal silver nanoparticles systems [20] with an average particle size between 10 and $20 \mathrm{~nm}$. However, the nanocomposite powder posseses an interesting advantage: it can be easily handled and shaped into pellets or sponges without special care
Table 1: Diffusion disk test of HA-nAg pellets, containing 10000 ppm of Ag, against Staphylococcus aureus, Pneumococcus, and Escherichia coli after 24 hours at $37^{\circ} \mathrm{C}$.

\begin{tabular}{lccc}
\hline & S. aureus & Pneumococcus & E. coli \\
\hline $\begin{array}{l}\text { Inhibition zone } \\
\text { diameter }( \pm 0.5 \mathrm{~mm})\end{array}$ & 17 & 17.5 & 18 \\
\hline
\end{tabular}

to avoid the typical agglomeration problems related to the colloidal systems of nanoparticles.

\section{Conclusions}

In summary, we have described a simple and low-cost method to obtain a HA-Ag nanocomposite powder with bactericidal properties. TEM, XRD, and UV-vis techniques have showed the presence of silver nanoparticles $(\sim 65 \mathrm{~nm})$ attached on the hydroxyapatite particles surface without a high degree of agglomeration. The bactericidal activity results show that this nanocomposite is strongly active against some of the most common Gram-positive and Gramnegative bacterial strains, so it can be considered as an antimicrobial biomaterial that can be used in implant and reconstructive surgery applications.

\section{Acknowledgments}

This work was supported by Bioker Research S.L. and by the Spanish Ministry of Education and Science under Project CENIT-INTELIMPLANT (ref.: 20071210). M. Díaz has been supported by Spanish Ministry of Education and Science and CSIC under I3P Program financed by European Social Fund. The authors thank Raul Pina for the technical support in the TEM study.

\section{References}

[1] "Orthopedic Procedures Increase Dramatically in Seven Years," Agency for Healthcare Research and Quality (AHRQ News and Numbers), Rockville, Md, USA, 2007, http://www.ahrq.gov/news/nn/nn071807.htm.

[2] E. E. MacHtei, D. Mahler, O. Oettinger-Barak, O. Zuabi, and J. Horwitz, "Dental implants placed in previously failed sites: survival rate and factors affecting the outcome," Clinical Oral Implants Research, vol. 19, no. 3, pp. 259-264, 2008.

[3] M. Jarcho, "Retrospective analysis of hydroxyapatite development for oral implant applications," Dental Clinics of North America, vol. 36, no. 1, pp. 19-26, 1992.

[4] M. Tirrell, E. Kokkoli, and M. Biesalski, "The role of surface science in bioengineered materials," Surface Science, vol. 500, no. 1-3, pp. 61-83, 2002.

[5] L. L. Hench, "Bioceramics," Journal of the American Ceramic Society, vol. 81, no. 7, pp. 1705-1728, 1998.

[6] W. Zimmerli, A. Trampuz, and P. E. Ochsner, "Current concepts: prosthetic-joint infections," The New England Journal of Medicine, vol. 351, no. 16, pp. 1645-1654, 2004.

[7] H. Malchau, G. Garelick, and P. Herberts, "The evidence from the Swedish hip register," in The Well-Cemented Total Hip Arthroplasty: Theory and Practice, S. Breusch and H. Malchau, Eds., pp. 291-301, Springer, Berlin, Germany, 2006. 
[8] A. Trampuz and W. Zimmerli, "Prosthetic joint infections: update in diagnosis and treatment," Swiss Medical Weekly, vol. 135, no. 17-18, pp. 243-251, 2005.

[9] R. O. Darouiche, "Treatment of infections associated with surgical implants," The New England Journal of Medicine, vol. 350, no. 14, pp. 1422-1429, 2004.

[10] S. Chen and I. Darby, "Dental implants: maintenance, care and treatment of peri-implant infection," Australian Dental Journal, vol. 48, no. 4, pp. 212-220, 2003.

[11] W. J. Leach and N. I. L. Wilson, "Trends in infection prophylaxis in orthopaedics," Journal of the Royal College of Surgeons of Edinburgh, vol. 37, no. 4, pp. 265-266, 1992.

[12] J. Calhoun, G. Cierny III, P. Holtom, J. Mader, and C. L. Nelson, "Symposium: current concepts in the management of osteomyelitis," Contemporary Orthopaedics, vol. 28, no. 2, pp. 157-185, 1994.

[13] T. N. Gerhart, R. D. Roux, P. A. Hanff, G. L. Horowitz, A. A. Renshaw, and W. C. Hayes, "Antibiotic-loaded biodegradable bone cement for prophylaxis and treatment of experimental osteomyelitis in rats," Journal of Orthopaedic Research, vol. 11, no. 2, pp. 250-255, 1993.

[14] P. Wu and D. W. Grainger, "Drug/device combinations for local drug therapies and infection prophylaxis," Biomaterials, vol. 27, no. 11, pp. 2450-2467, 2006.

[15] E. M. Hetrick and M. H. Schoenfisch, "Reducing implantrelated infections: active release strategies," Chemical Society Reviews, vol. 35, no. 9, pp. 780-789, 2006.

[16] A. Sudo, M. Hasegawa, A. Fukuda, and A. Uchida, "Treatment of infected hip arthroplasty with antibiotic-impregnated calcium hydroxyapatite," The Journal of Arthroplasty, vol. 23, no. 1, pp. 145-150, 2008.

[17] J. S. Price, A. F. Tencer, D. M. Arm, and G. A. Bohach, "Controlled release of antibiotics from coated orthopedic implants," Journal of Biomedical Materials Research, vol. 30, no. 3, pp. 281-286, 1996.

[18] S. L. Percival, P. G. Bowler, and D. Russell, "Bacterial resistance to silver in wound care," Journal of Hospital Infection, vol. 60, no. 1, pp. 1-7, 2005.

[19] D. Lee, R. E. Cohen, and M. F. Rubner, "Antibacterial properties of Ag nanoparticle loaded multilayers and formation of magnetically directed antibacterial microparticles," Langmuir, vol. 21, no. 21, pp. 9651-9659, 2005.

[20] I. Sondi and B. Salopek-Sondi, "Silver nanoparticles as antimicrobial agent: a case study on E. coli as a model for Gramnegative bacteria," Journal of Colloid and Interface Science, vol. 275, no. 1, pp. 177-182, 2004.

[21] A. R. Shahverdi, A. F. Pharm, H. R. Shahverdi, and S. Minaian, "Synthesis and effect of silver nanoparticles on the antibacterial activity of different antibiotics against Staphylococcus aureus and Escherichia coli," Nanomedicine: Nanotechnology, Biology and Medicine, vol. 3, no. 2, pp. 168-171, 2007.

[22] A. Panáček, L. Kvítek, R. Prucek, et al., "Silver colloid nanoparticles: synthesis, characterization, and their antibacterial activity," Journal of Physical Chemistry B, vol. 110, no. 33, pp. 16248-16253, 2006.

[23] K. Dunn and V. Edwards-Jones, Eds., "The role of Acticoat ${ }^{\mathrm{TM}}$ with nanocrystalline silver in the management of burns," Burns, vol. 30, supplement 1, pp. S1-S9, 2004.

[24] K.-H. Cho, J.-E. Park, T. Osaka, and S.-G. Park, "The study of antimicrobial activity and preservative effects of nanosilver ingredient," Electrochimica Acta, vol. 51, no. 5, pp. 956-960, 2005.
[25] R. Kumar and H. Münstedt, "Silver ion release from antimicrobial polyamide/silver composites," Biomaterials, vol. 26, no. 14, pp. 2081-2088, 2005.

[26] M. Bellantone, H. D. Williams, and L. L. Hench, "Broadspectrum bactericidal activity of $\mathrm{Ag}_{2} \mathrm{O}$-doped bioactive glass," Antimicrobial Agents and Chemotherapy, vol. 46, no. 6, pp. 1940-1945, 2002.

[27] V. Alt, T. Bechert, P. Steinrücke, et al., "An in vitro assessment of the antibacterial properties and cytotoxicity of nanoparticulate silver bone cement," Biomaterials, vol. 25, no. 18, pp. 4383-4391, 2004.

[28] V. Sambhy, M. M. MacBride, B. R. Peterson, and A. Sen, "Silver bromide nanoparticle/polymer composites: dual action tunable antimicrobial materials," Journal of the American Chemical Society, vol. 128, no. 30, pp. 9798-9808, 2006.

[29] W. Chen, S. Oh, A. P. Ong, et al., "Antibacterial and osteogenic properties of silver-containing hydroxyapatite coatings produced using a sol gel process," Journal of Biomedical Materials Research Part A, vol. 82, no. 4, pp. 899-906, 2007.

[30] R.-J. Chung, M.-F. Hsieh, K.-C. Huang, L.-H. Perng, F.I. Chou, and T.-S. Chin, "Anti-microbial hydroxyapatite particles synthesized by a sol-gel route," Journal of Sol-Gel Science and Technology, vol. 33, no. 2, pp. 229-239, 2005.

[31] N. Rameshbabu, T. S. Sampath Kumar, T. G. Prabhakar, V. S. Sastry, K. V. G. K. Murty, and K. Prasad Rao, "Antibacterial nanosized silver substituted hydroxyapatite: synthesis and characterization," Journal of Biomedical Materials Research Part A, vol. 80, no. 3, pp. 581-591, 2007.

[32] I.-H. Han, I.-S. Lee, J.-H. Song, et al., "Characterization of a silver-incorporated calcium phosphate film by RBS and its antimicrobial effects," Biomedical Materials, vol. 2, no. 3, pp. S91-S94, 2007.

[33] W. Chen, Y. Liu, H. S. Courtney, et al., "In vitro anti-bacterial and biological properties of magnetron co-sputtered silvercontaining hydroxyapatite coating," Biomaterials, vol. 27, no. 32, pp. 5512-5517, 2006.

[34] S. K. Arumugam, T. P. Sastry, B. Sreedhar, and A. B. Mandal, "One step synthesis of silver nanorods by autoreduction of aqueous silver ions with hydroxyapatite: an inorganicinorganic hybrid nanocomposite," Journal of Biomedical Materials Research Part A, vol. 80, no. 2, pp. 391-398, 2007.

[35] M. Pourbaix, Atlas of Electrochemical Equilibria in Aqueous Solutions, National Association of Corrosion Engineers, Houston, Tex, USA, 1974.

[36] B. L. Cushing, V. L. Kolesnichenko, and C. J. O'Connor, "Recent advances in the liquid-phase syntheses of inorganic nanoparticles," Chemical Reviews, vol. 104, no. 9, pp. 38933946, 2004. 

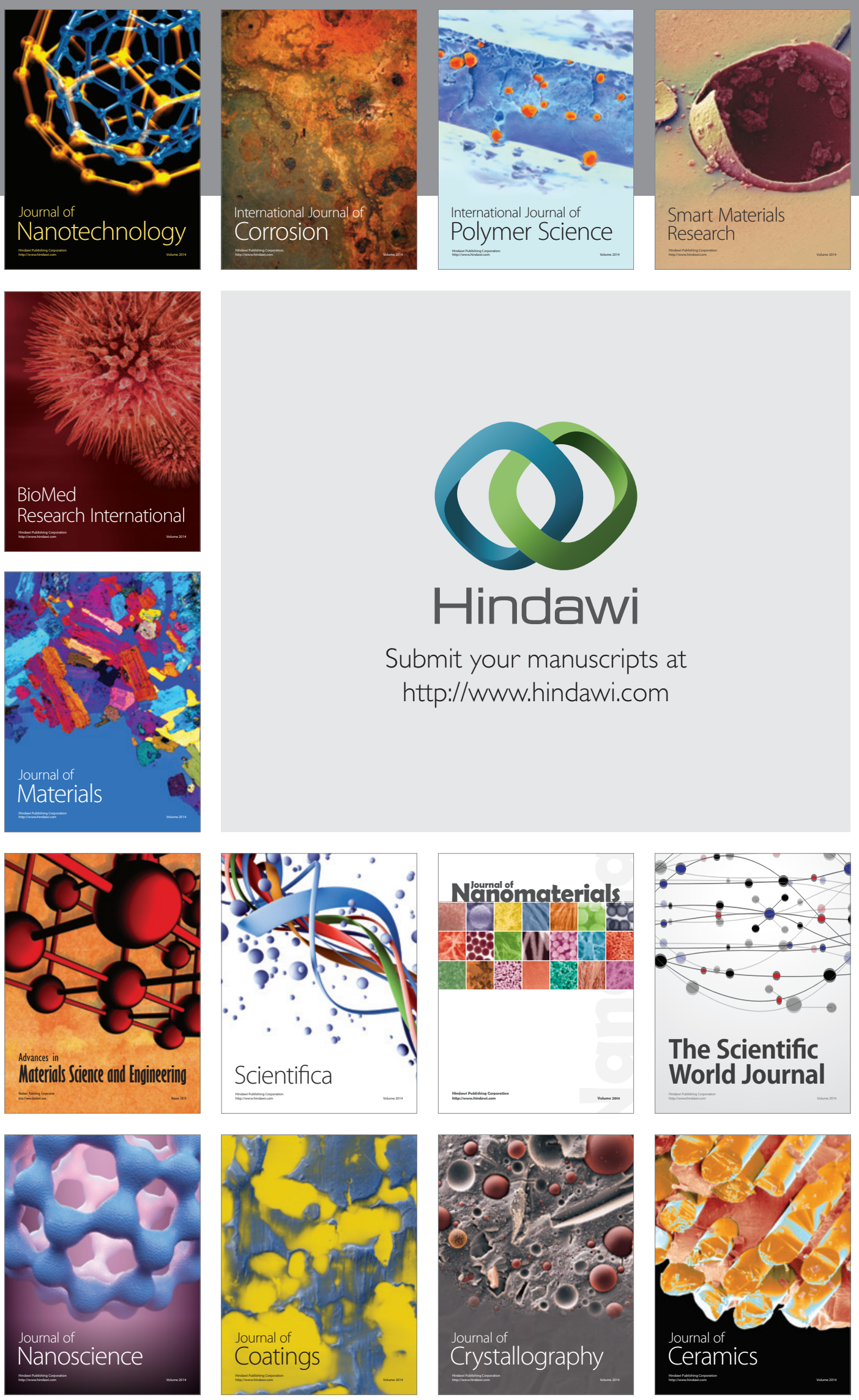

The Scientific World Journal

Submit your manuscripts at

http://www.hindawi.com

\section{World Journal}

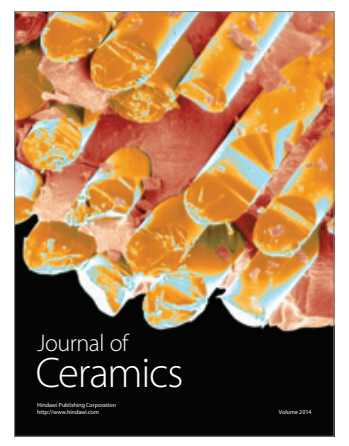

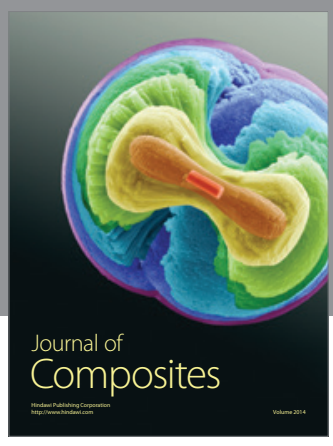
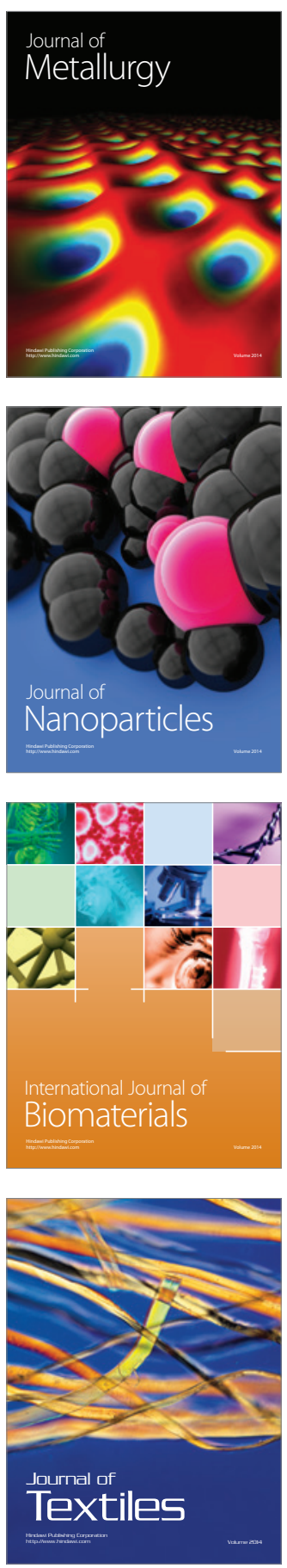